Hans-Ulrich Krause

Ganzheitliches Reporting mit Kennzahlen im Zeitalter der digitalen Vernetzung 



\section{Hans-Ulrich Krause}

\section{Ganzheitliches Reporting mit Kennzahlen im Zeitalter der digitalen Vernetzung}

Ein fallstudienbegleiteter Ansatz zur NachhaltigkeitsImplementierung

2., überarbeitete, aktualisierte und ergänzte Auflage 
ISBN 978-3-11-059702-8

e-ISBN (PDF) 978-3-11-059703-5

e-ISBN (EPUB) 978-3-11-059964-0

Library of Congress Control Number: 2018967602

Bibliografische Information der Deutschen Nationalbibliothek

Die Deutsche Nationalbibliothek verzeichnet diese Publikation in der Deutschen Nationalbibliografie; detaillierte bibliografische Daten sind im Internet über http://dnb.dnb.de abrufbar.

(C) 2019 Walter de Gruyter GmbH, Berlin/Boston

Einbandabbildung: cifotart / iStock / Getty Images Plus

Satz: Michael Peschke

Druck und Bindung: CPI books GmbH, Leck

www.degruyter.com 